\title{
Safety and Effectiveness of Ixazomib Dose-escalating Strategy in Ixazomib-Lenalidomide-Dexamethasone Treatment for Relapsed/Refractory Multiple Myeloma
}

\author{
YASUKATA OHASHI ${ }^{1,2}$, MEGUMI YATABE ${ }^{1}$, DAISUKE NIIJIMA ${ }^{1}$, KENTARO TANI $^{1}$, \\ CHIAKI OGAWA ${ }^{1}$, YUTAKA YACHI $^{1}$, TOSHIYA KAGOO ${ }^{3}$, SAIGEN BOKU $^{3}$, \\ HIRONORI UENO ${ }^{3}$, TAKAHIRO YANO ${ }^{3}$, KOJI HIGAI ${ }^{2}$ and AKIHIRO YOKOYAMA ${ }^{3,4}$ \\ ${ }^{1}$ Department of Pharmacy, National Hospital Organization Tokyo Medical Center, Tokyo, Japan; \\ ${ }^{2}$ Laboratory of Medical Biochemistry, Faculty of Pharmaceutical Sciences Toho University, Chiba, Japan; \\ ${ }^{3}$ Division of Hematology, National Hospital Organization Tokyo Medical Center, Tokyo, Japan; \\ ${ }^{4}$ Division of Transfusion Medicine, National Hospital Organization Tokyo Medical Center, Tokyo, Japan
}

\begin{abstract}
Background/Aim: Gastrointestinal toxicity is common in patients receiving common therapy of ixazomib with lenalidomide and low-dose dexamethasone (IRd) for relapsed/refractory multiple myeloma. Here, we investigated the safety and effectiveness of ixazomib dosing schedules. Patients and Methods: We retrospectively evaluated 17 consecutive patients treated with IRd (10 patients on ixazomib doseescalation strategy (2.3 $\mathrm{mg}$ starting dose); seven patients on standard dose). Results: The incidence of grade 3 or more haematological and grade 2 or more non-haematological adverse events was lower in the dose-escalation group than in the standard-dose group, and only that of diarrhoea was significantly lower. The median time to treatment interruption was significantly longer in the dose-escalation group than in the standard-dose group. There was no significant difference in the overall response rate (20\% vs. $43 \%)$ and disease control rate (70\% vs. $86 \%)$. Conclusion: A dose-escalation strategy to optimise ixazomib dosing may reduce treatment interruption due to adverse events without compromising its antitumor activity.
\end{abstract}

Proteasome inhibitor and immunomodulatory drugs have markedly improved the overall survival of patients with multiple myeloma (MM) (1). Various other drugs, including

This article is freely accessible online.

Correspondence to: Yasukata Ohashi, Department of Pharmacy, National Hospital Organization Tokyo Medical Center, 2-5-1 Higashigaoka Meguro-ku, Tokyo 152-8902, Japan. Tel: +81 334110111, Fax: +81 334115488, E-mail: yasu970554126@gmail.com

Key Words: Ixazomib, dose-escalation, lenalidomide, safety, effectiveness, relapsed/refractory multiple myeloma. monoclonal antibodies, have also been introduced (2). In addition, treatment has evolved from doublet therapy to use of three or more agents in combination therapy, regardless of transplantation eligibility (3).

Ixazomib is an attractive drug as the first oral proteasome inhibitor to be approved in Japan in March 2017. In combination with lenalidomide and dexamethasone, a fixed dose of $4 \mathrm{mg}$ ixazomib is the usual dose for patients with relapsed/refractory MM. While ixazomib, lenalidomide and dexamethasone (combination therapy as IRd) can be administered only orally, the associated gastrointestinal toxicities, such as diarrhoea, nausea, and vomiting, tend to be more frequent and severe than in triplet therapy that includes other proteasome inhibitors such as bortezomib and carfilzomib (4-6). Furthermore, the number of patients at the time of clinical development of IRd in Japan was extremely small. In a global, phase III, double-blind, placebo-controlled study on IRd, Only 20 Japanese patients were included in the experimental arm (4), although 14 patients were included in a Japanese phase I study (7). To our best knowledge, there are currently no real-world data on dose-modified IRd in the Japanese population.

Japan has the highest proportion of people over the age of 65 years in the world (8). According to a previous report comparing the domestic incidence of MM between 19902000 and 2001-2012 in Japan, there was no difference in the median age at diagnosis. However, the proportion of those aged 75 years or older increased from $29.7 \%$ to $32.4 \%$ (9). In patients with relapsed/refractory MM, many of whom are elderly with impaired organ function, concerns have been raised about increased toxicity with IRd using the standard dose of ixazomib.

Dose escalation for reducing adverse events (AEs) while maintaining effectiveness has been recently evaluated, including in molecular targeted drugs for colorectal cancer 
A Dose-escalation group $(\mathrm{n}=10)$

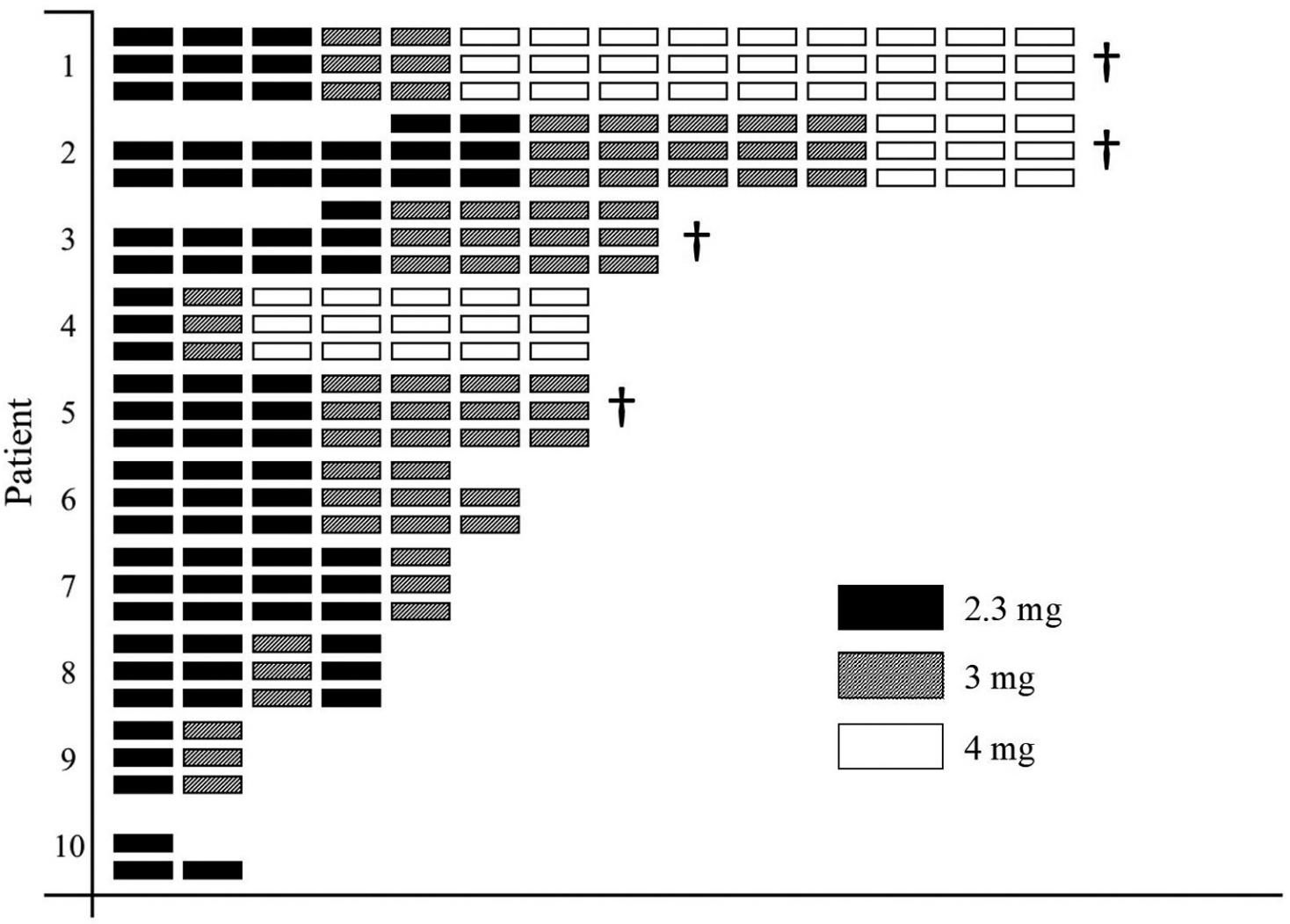

B Standard-dose group $(\mathrm{n}=7)$

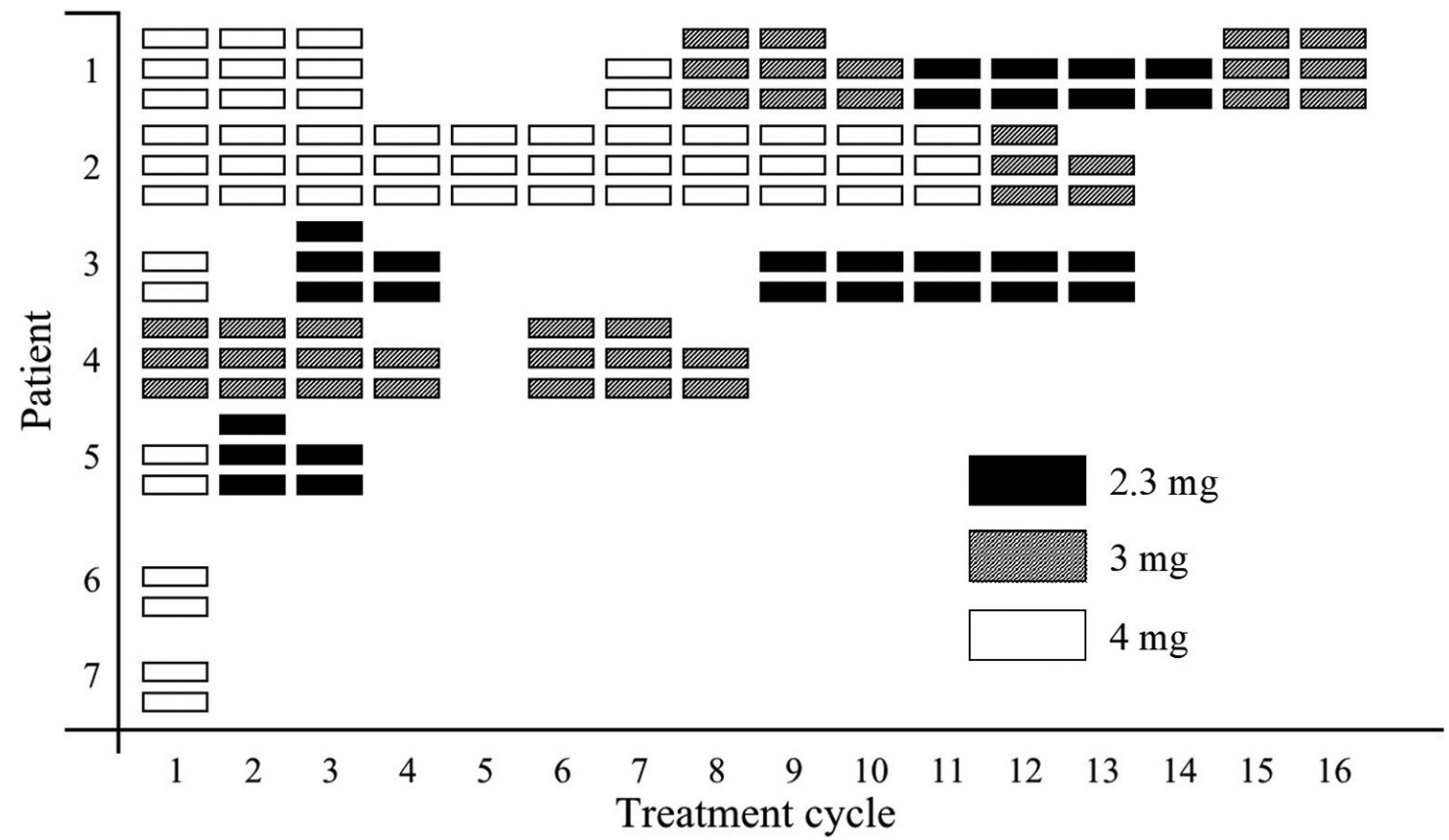

Figure 1. Swimmer plot presenting ixazomib dosing history up to the cut-off date in dose-escalation (A) and standard-dose (B) groups. Individual patients are represented throughout the different cycles by a horizontal series of bars. There are up to three doses of ixazomib in one cycle, and each dose is represented by a rectangle. ${ }^{\dagger}$ Censored case. 
Table I. Patient characteristics.

\begin{tabular}{|c|c|c|c|c|}
\hline \multicolumn{2}{|l|}{ Characteristic } & \multirow{2}{*}{$\frac{\text { DE group }(n=10)}{75(68-85)}$} & \multirow{2}{*}{$\frac{\text { SD group }(\mathrm{n}=7)}{78(68-81)}$} & \multirow{2}{*}{$\frac{p \text {-Value }}{0.62}$} \\
\hline Age, years & Median (range) & & & \\
\hline \multirow{2}{*}{ Age, $\mathrm{n}(\%)$} & $\geq 70$ Years & $8(80)$ & $5(71)$ & \\
\hline & $\geq 75$ Years & $4(40)$ & $2(29)$ & \\
\hline Male sex, $\mathrm{n}(\%)$ & $7(70)$ & $3(43)$ & 0.35 & \\
\hline \multirow[t]{2}{*}{ ECOG PS, n (\%) } & 0,1 & $6(60)$ & $7(100)$ & 0.10 \\
\hline & 2 & $4(40)$ & $0(0)$ & \\
\hline \multirow[t]{3}{*}{ ISS at initial diagnosis, $\mathrm{n}(\%)$} & I & $5(50)$ & $1(14)$ & 0.47 \\
\hline & II & $3(30)$ & $3(43)$ & \\
\hline & III & $2(20)$ & $3(43)$ & \\
\hline \multirow[t]{2}{*}{ Myeloma subtype, n (\%) } & IgG & $7(70)$ & $6(86)$ & 0.60 \\
\hline & $\operatorname{IgA}$ & $3(30)$ & $1(14)$ & \\
\hline \multirow{2}{*}{ Cytogenetic features, n (\%) } & Standard risk & $10(100)$ & $5(71)$ & 0.15 \\
\hline & High risk & $0(0)$ & $2(29)$ & \\
\hline Time from diagnosis, months & Median (range) & $125(67-285)$ & $78(38-198)$ & 0.06 \\
\hline Body surface area, $\mathrm{m}^{2}$ & Median (range) & $1.58(1.11-1.74)$ & $1.55(1.20-1.82)$ & 0.60 \\
\hline $\mathrm{CrCl}, \mathrm{ml} / \mathrm{min}$ & Median (range) & $54(22-88)$ & $48(17-71)$ & 0.42 \\
\hline \multirow[t]{2}{*}{ Charlson Comorbidity Index, n (\%) } & 0,1 & $6(60)$ & $2(29)$ & 0.34 \\
\hline & $\geq 2$ & $4(40)$ & $5(71)$ & \\
\hline \multirow[t]{3}{*}{ Number of prior therapies, n (\%) } & 1 & $0(0)$ & $1(14)$ & 0.47 \\
\hline & 2 & $5(50)$ & $2(29)$ & \\
\hline & $\geq 3$ & $5(50)$ & $4(57)$ & \\
\hline Prophylactic anti-emetics, n (\%) & Yes & $9(90)$ & $5(71)$ & 0.54 \\
\hline Antidiarrheal drug prescription, $\mathrm{n}(\%)$ & Yes & $9(90)$ & $5(71)$ & 0.54 \\
\hline \multirow[t]{10}{*}{ Prior treatment, $\mathrm{n}(\%)$} & Bortezomib & $10(100)$ & $7(100)$ & 0.71 \\
\hline & Thalidomide & $1(10)$ & $2(29)$ & \\
\hline & Lenalidomide & $10(100)$ & $5(71)$ & \\
\hline & Pomalidomide & $1(10)$ & $0(0)$ & \\
\hline & Melphalan & $1(10)$ & $1(14)$ & \\
\hline & Dexamethasone & $10(100)$ & $7(100)$ & \\
\hline & Cyclophosphamide & $0(0)$ & $2(29)$ & \\
\hline & Panobinostat & $1(10)$ & $0(0)$ & \\
\hline & Elotuzumab & $1(10)$ & $0(0)$ & \\
\hline & $\mathrm{SCT}$ & $2(20)$ & $0(0)$ & \\
\hline Intolerance to latest treatment, $\mathrm{n}(\%)$ & Yes & $0(0)$ & $1(14)$ & 0.41 \\
\hline \multirow[t]{3}{*}{ Refractory to prior therapy, $\mathrm{n}(\%)$} & Lenalidomide & $2(20)$ & $1(14)$ & 0.64 \\
\hline & Bortezomib & $0(0)$ & $1(14)$ & \\
\hline & Both & $4(40)$ & $1(14)$ & \\
\hline
\end{tabular}

SD: Standard-dose group; DE: dose-escalation group; ECOG PS: Eastern Cooperative Oncology Group performance status; ISS: International Staging System; CrCl: creatinine clearance; SCT: stem cell transplantation. Cytogenetic feature of high risk indicates having the pattern of del 17p, $\mathrm{t}(4: 14), \mathrm{t}(14: 16)$.

(10) and immunomodulatory drugs for chronic lymphocytic leukaemia (11). This study aimed to evaluate the safety and effectiveness of dose escalation of ixazomib from low doses for relapsed/refractory MM.

\section{Patients and Methods}

Patients and study design. The retrospective study evaluated consecutive patients with relapsed/refractory MM who received IRd at the National Hospital Organization Tokyo Medical Center (Tokyo, Japan) between June 2017 and December 2018. Patient information was obtained from medical records. Data were collected on patient characteristics, including sex, age, Eastern Cooperative
Oncology Group performance status, International Staging System category at diagnosis, myeloma subtype, cytogenetic abnormalities, time from diagnosis, creatinine clearance $(\mathrm{CrCl})$ estimated using the Cockcroft-Gault equation, Charlson Comorbidity Index, prophylactic antiemetic medication, antidiarrhoeal drug prescription, prior treatment, intolerance to latest treatment, and refractoriness of bortezomib and lenalidomide. This study was performed according to the principles set out in the 1964 Declaration of Helsinki and all subsequent revisions and was approved by the Ethics Committee at National Hospital Organization Tokyo Medical Center (R19-063). Treatment. IRd therapy consisted of three different agents: ixazomib, lenalidomide, and low-dose dexamethasone. Ixazomib was administered on days 1,8 , and 15 of each 28 -day cycle, with lenalidomide on days 1-21 and dexamethasone on days $1,8,15$, and 
Table II. Dosing information for therapy using ixazomib combined with lenalidomide and low-dose dexamethasone.

\begin{tabular}{lccc}
\hline Characteristic & $\begin{array}{c}\text { DE group } \\
(\mathrm{n}=10)\end{array}$ & $\begin{array}{c}\text { SD group } \\
(\mathrm{n}=7)\end{array}$ & $p$-Value \\
\hline $\begin{array}{c}\text { Starting dose, } \mathrm{n}(\%) \\
\text { Ixazomib }\end{array}$ & & & \\
$4 \mathrm{mg} /$ day & $0(0)$ & $6(86)$ & - \\
$3 \mathrm{mg} /$ day & $0(0)$ & $1(14)$ & - \\
$2.3 \mathrm{mg} /$ day & $10(100)$ & $0(0)$ & \\
Lenalidomide & & $2(29)$ & \\
$25 \mathrm{mg} /$ day & $3(30)$ & $2(29)$ & 0.90 \\
$15 \mathrm{mg} /$ day & $4(40)$ & $3(42)$ & \\
$10 \mathrm{mg} /$ day & $2(20)$ & $0(0)$ & \\
$5 \mathrm{mg} /$ day & $1(10)$ & $1(14)$ & \\
Dexamethasone & & $4(57)$ & 0.11 \\
$40 \mathrm{mg} /$ day & $0(0)$ & $2(29)$ & \\
$20 \mathrm{mg} /$ day & $8(80)$ & $0(0)$ & \\
$8 \mathrm{mg} /$ day & $0(0)$ & & \\
$4 \mathrm{mg} /$ day & $2(20)$ & & \\
Cumulative dose, mg & & & \\
Ixazomib & & & \\
Median (IQR) & $46.2(31.4-71.9)$ & $42.5(13.8-94.2)$ & 0.92 \\
Lenalidomide & & & \\
Median (IQR) & $1,560(1,050-2,415)$ & $770(368-2,503)$ & 0.24 \\
Dexamethasone & & & \\
Median (IQR) & $352(157-530)$ & $416(110-556)$ & 0.92 \\
\hline
\end{tabular}

SD: Standard-dose group; DE: dose-escalation group; IQR: interquartile range.

22. The doses of lenalidomide and dexamethasone were determined by each physician according to the patient's age, performance status, comorbidities, and renal function. Patients were divided into two groups according to the starting dose of ixazomib: The standard-dose (SD) group, i.e. starting dose of $4 \mathrm{mg}$ according to the Japanese package insert; and the dose-escalation (DE) group, i.e. starting dose of $2.3 \mathrm{mg}$ ixazomib with dose escalation up to $4 \mathrm{mg}$ according to tolerability. The starting dose of $2.3 \mathrm{mg}$ was adopted because it was the lowest dose that could be used in clinical practice and that was the SD or higher in the phase I study with ixazomib alone (12). Dose titration of ixazomib was performed at the discretion of each physician. In cases with AEs, the dose was reduced; otherwise, IRd administration was suspended until recovery from the AEs. IRd was administered until disease progression, unacceptable toxicity, or the decision to discontinue by the patient or the physician. At the start of the treatment, pharmacists interviewed and explained in detail how to take the constituent drugs of IRd therapy, including antidiarrhoeal drugs, and prophylactic antiemesis for all patients regardless of ambulatory practice or hospitalisation. The pharmacists then continued interviews to check medication adherence and monitor AEs at every subsequent outpatient visit. The IRd dosing information, such as starting dose and cumulative dose of each drugs was examined. A swimmer plot was drawn to clearly show the dosing history of ixazomib (Figure 1).

Safety and effectiveness. Dose modification, time to treatment interruption and discontinuation (TTD), and the incidence of treatment discontinuation due to AEs were examined. The severity
Table III. Drug-related adverse events according to Common Terminology Criteria for Adverse Events ver 4.03 (13).

\begin{tabular}{lccr}
\hline $\begin{array}{l}\text { Adverse events, } \\
\mathrm{n}(\%)\end{array}$ & $\begin{array}{c}\text { DE group } \\
(\mathrm{n}=10)\end{array}$ & $\begin{array}{c}\text { SD group } \\
(\mathrm{n}=7)\end{array}$ & $p$-Value \\
\hline $\begin{array}{l}\text { Hematological (grade } \geq 3) \\
\quad\end{array}$ & $2(20)$ & $3(43)$ & 0.59 \\
$\quad$ Thrombocytopenia & $1(10)$ & $3(43)$ & 0.25 \\
Neutropenia & $1(10)$ & $3(43)$ & 0.25 \\
Anemia & $0(0)$ & $0(0)$ & $>0.99$ \\
$\quad$ Febrile neutropenia & & & \\
Non-hematological (grade $\geq 2)$ & $7(70)$ & $6(86)$ & 0.60 \\
Fatigue & $6(60)$ & $4(57)$ & $>0.99$ \\
Constipation & $2(20)$ & $3(43)$ & 0.59 \\
Skin rash & $2(20)$ & $2(29)$ & $>0.99$ \\
Peripheral neuropathy & $1(10)$ & $2(29)$ & 0.54 \\
Insomnia & $0(0)$ & $4(57)$ & $\mathbf{0 . 0 1}$ \\
Diarrhea & $0(0)$ & $2(29)$ & 0.15 \\
Vomiting & $0(0)$ & $2(29)$ & 0.15 \\
Nausea & $0(0)$ & $1(14)$ & 0.41 \\
Herpes zoster & $0(0)$ & $0(0)$ & $>0.99$ \\
Venous thromboembolism & & \\
\hline
\end{tabular}

SD: Standard-dose group; DE: dose-escalation group. Bold value indicates statistical significance.

of AEs was classified according to the Common Terminology Criteria for Adverse Events, version 4.03 (13). The TTD was defined as the time from initiation of IRd treatment until the last dose recorded as one aspect of evaluating effectiveness (14). Time to treatment interruption was also defined as the time from initiation of IRd treatment until the first dose missed (inability to take ixazomib due to any cause) or the last dose recorded within the follow-up. MM disease response was assessed by physicians in accordance with the uniform criteria of the International Myeloma Working Group (15).

Statistical analysis. Fisher's exact test and Mann-Whitney $U$-test were used for between-group comparisons of categorical and numerical data, respectively. The Kaplan-Meier method was used to calculate the TTD. The significance of the TTD in each group was tested using a generalised Wilcoxon test. All $p$-values were twosided, and values less than 0.05 were considered significant. All statistical analyses were performed using EZR (Easy R) version 1.40 (Saitama Medical Center, Jichi Medical University, Saitama, Japan) (16).

\section{Results}

Patient characteristics. Of the 17 patients included in the analysis, 10 (median age $=75$ years) and seven (median age $=78$ years) patients were categorised into the DE and the SD groups, respectively. The baseline characteristics of the 17 patients are listed in Table I. The baseline characteristics were mostly comparable between group. Although the percentage of male patients $(70 \%$ vs. $43 \%)$, patients with Eastern Cooperative Oncology Group performance status 2 (40\% vs. $0 \%$ ), patients receiving prophylactic antiemetic medication 


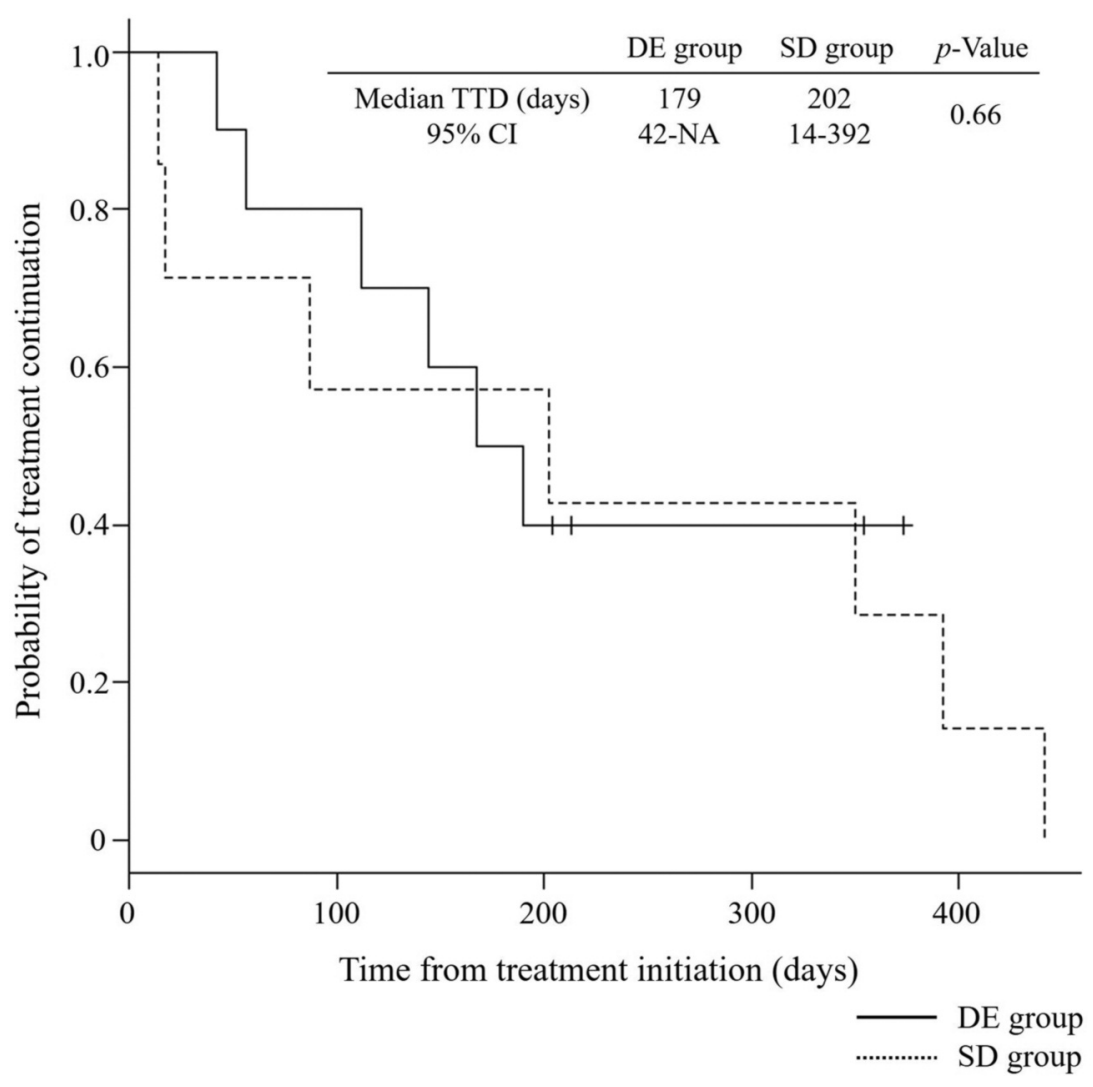

Figure 2. Kaplan-Meier plots of time to treatment discontinuation (TTD) in the dose-escalation (DE) and standard-dose (SD) groups. Censored patients are marked on the curves with a cross. CI: Confidence interval; NA: Not applicable.

Table IV. Treatment modification.

\begin{tabular}{lccc}
\hline & $\begin{array}{c}\text { DE group } \\
(\mathrm{n}=10)\end{array}$ & $\begin{array}{c}\text { SD group } \\
(\mathrm{n}=7)\end{array}$ & $p$-Value \\
\hline $\begin{array}{l}\text { Median (IQR) time to } \\
\text { treatment interruption, days }\end{array}$ & $179(120-207)$ & $17(13.5-77)$ & $\mathbf{0 . 0 4}$ \\
$\begin{array}{l}\text { Ixazomib dose reduction } \\
\text { due to AEs, n (\%) }\end{array}$ & $2(20)$ & $6(86)$ & $\mathbf{0 . 0 1}$ \\
$\begin{array}{l}\text { Treatment discontinuation due } \\
\text { due to AEs, n (\%) }\end{array}$ & $2(20)$ & $6(86)$ & $\mathbf{0 . 0 1}$ \\
\hline
\end{tabular}

SD: Standard-dose group; DE: dose-escalation group; IQR: interquartile range; AEs: adverse events. Bold values indicate statistical significance.

(90\% vs. $71 \%)$ and antidiarrhoeal drug prescription (90\% vs. $71 \%)$, and those refractory to prior bortezomib and lenalidomide (40\% vs. 14\%) was higher in the DE group than in the SD group, there was no significant difference.

Treatment. IRd dosing information is shown in Table II. Except for one patient, all other patients in the SD group started with $4 \mathrm{mg}$ of ixazomib. This patient started treatment
Table V. Best response to therapy using ixazomib combined with lenalidomide and low-dose dexamethasone.

\begin{tabular}{lccc}
\hline & $\begin{array}{c}\text { DE group } \\
(\mathrm{n}=10)\end{array}$ & $\begin{array}{c}\text { SD group } \\
(\mathrm{n}=7)\end{array}$ & $p$-Value \\
\hline Stringent complete response & $2(20)$ & $0(0)$ & 0.14 \\
Complete response & $0(0)$ & $0(0)$ & \\
Partial response & $0(0)$ & $3(43)$ & \\
Stable disease & $5(50)$ & $3(43)$ & \\
Progressive disease & $3(30)$ & $1(14)$ & \\
Overall response ( $\geq$ Partial response) & $2(20)$ & $3(43)$ & 0.59 \\
Disease control ( $\geq$ Stable disease) & $7(70)$ & $6(86)$ & 0.60 \\
\hline & & & \\
\hline
\end{tabular}

with $3 \mathrm{mg}$ of ixazomib according to the US package insert because their $\mathrm{CrCl}$ was less than $30 \mathrm{ml} / \mathrm{min}$. The starting dose of lenalidomide and dexamethasone was generally based on the age-specific dose setting proposed by Palumbo et al. (17). Because one patient who started lenalidomide at $5 \mathrm{mg}$ in the DE group had severe renal dysfunction $(\mathrm{CrCl}<30 \mathrm{ml} / \mathrm{min})$ and two patients who started dexamethasone at 4 or $8 \mathrm{mg}$ in both groups were under treatment for diabetes, the starting 
dose of each drug was reduced. The median cumulative doses of ixazomib, lenalidomide, and dexamethasone in the DE and SD groups were 46.2, 1,560 and $352 \mathrm{mg}$ and 42.5, 770 and $416 \mathrm{mg}$, respectively, with no significant difference. At the cut-off of May 30, 2019, the median follow-up of the whole patient cohort was 373 days (interquartile range $=191-700$ days). Ixazomib dosing history by treatment groups until the cut-off date is summarised in Figure 1.

Safety and effectiveness. The AEs experienced by patients under IRd therapy are shown in Table III. The incidence of both grade 3 or more haematological and grade 2 or more non-haematological AEs was generally lower in the DE group than in the SD group, with diarrhoea being significantly lower $(0 \%$ vs. $57 \%, p=0.01)$. Treatment interruption within 30 days from initiation occurred in three patients in the SD group due to grade 3 events of diarrhoea, vomiting and skin rash, and in one patient in the DE group due to grade 3 fatigue. The median time to treatment interruption was significantly longer in the DE than in the SD group (179 vs. 17 days, $p=0.01$ ) (Table IV). In addition, ixazomib dose reductions because of AEs were needed in two $(20 \%)$ patients in the DE group and in six (86\%) patients in the SD group. Treatment was discontinued due to AEs in two $(20 \%)$ patients in the DE group and in six (86\%) patients in the SD group. The reasons for discontinuation of the treatment regimen were fatigue and oedema of the lower limbs in the DE group, and fatigue, diarrhoea, skin rash, anaemia and, in two patients, reduced vision/headache in the SD group.

There were no significant differences in the overall response rate $(20 \% v s .43 \%)$ or disease control rate $(70 \% v s$. $86 \%$ ) between the two groups (Table V). Two cases of stringent complete response were observed in the DE group, neither of which were resistant to bortezomib and lenalidomide. As shown in Figure 2, the median TTD was 179 days ( $95 \%$ confidence interval $=42$ days-not reached) in the DE group and was 202 days $(95 \%$ confidence intervaI=14-392 days) in the SD group, with no significant difference.

\section{Discussion}

To the best of our knowledge, this is the first report of realworld data on dose-modified IRd therapy for patients with relapsed/refractory MM. In this study, we compared the safety and effectiveness between a starting dose of $4 \mathrm{mg}$ ixazomib (SD group), which was recommended in previous large-scale clinical trials, and a starting dose of $2.3 \mathrm{mg}$ with dose escalation (DE group). While the DE group had fewer treatment interruptions due to AEs and a lower rate of treatment discontinuation due to AEs compared to the SD group, there was no significant difference in the response rate or the TTD between the two groups. In the DE group, there were two cases of stringent complete response. The findings of this study show that a deep response can be obtained by appropriate titration even when starting from a low dose.

Pharmacokinetic analysis of ixazomib in patients with organ dysfunction showed that the exposure to ixazomib increased in patients with severe renal dysfunction $(\mathrm{CrCl}<30$ $\mathrm{ml} / \mathrm{min}$ ) and moderate (total bilirubin: 1.5-3 times higher than the upper limit of normal, with any aspartate aminotransferase level) to severe liver dysfunction (total bilirubin: 3-fold higher than the upper limit of normal, with any aspartate aminotransferase level) compared to the general patient population. It was therefore recommended that the starting dose of ixazomib be reduced from 4 to $3 \mathrm{mg}$ $(18,19)$. Gupta et al. reported that exposure to ixazomib tended to increase with increasing age, with decreasing body surface area (BSA), and with decreasing $\mathrm{CrCl}$, but that it was not always necessary to reduce the dose of ixazomib according to these (20).

There were also several reports on differences in ixazomib exposure by race, particularly between Westerners and Asians. Gupta et al. compared dose-normalised area under the concentration-time curve (AUC) data for East Asian patients with pooled historical data from Western patients. They reported higher systemic exposures in East Asian patients (28\% on day $1,49 \%$ on day 15) (21). Although Hou et al. also reported that the mean AUC for ixazomib in Chinese patients was $80 \%$ higher than in Western patients, the higher exposure did not appear to translate into a greater incidence of AEs (22). Based on the view that ixazomib toxicity is reversible and can be managed by dose reduction, the recommended dose of ixazomib for subsequent clinical trials in Asians, including Japanese, has been $4 \mathrm{mg}$. However, these conclusions are based on patient data under clinical trials that meet strict eligibility criteria. The interpatient variability in exposure may be high, particularly in clinical practice involving many elderly patients.

The proportion of dose reduction and treatment discontinuation due to AEs in the SD group (86\% and $86 \%$, respectively) in this study was higher than that in previous clinical trials (11-57\% and 6.5-21\%, respectively) $(4,7,12$, $23,24)$. In an analysis of 114 patients in whom treatment was discontinued after fewer than six cycles in Japanese post-marketing surveillance, $60(53 \%)$ patients discontinued treatment due to AEs. The main reason for discontinuation was diarrhoea $(n=15,25 \%)$, thrombocytopenia $(n=12,20 \%)$, vomiting $(n=9,15 \%)$, and nausea $(n=4,6.7 \%)(25)$. In the current study, among grade 2 or more non-haematological toxicities, only diarrhoea differed significantly in incidence between the two groups. Although there was one patient in the DE group and two in the SD group that were not prescribed antidiarrhoeal drugs and prophylactic antiemesis, the reason for the discontinuation of these patients was not 
gastrointestinal toxicity (such as diarrhoea, nausea, and vomiting) but rather grade 3 skin rash and progressive disease.

In this study, the median age was 75 years for the DE group and 78 years for the SD group. This was older compared to the 58-66 years in previous clinical trials including in Japan $(4,7,12,23,24)$. The median $\mathrm{CrCl}$ was also 54 and $48 \mathrm{ml} / \mathrm{min}$, and this was lower compared to 74$81 \mathrm{ml} / \mathrm{min}$ in past studies (23). In the previous large-scale clinical trial using ixazomib, there was no description of BSA; thus, a direct comparison was not possible (4). However, the median BSA of $1.55 \mathrm{~m}^{2}$ (range=1.20-1.82) in this study is almost the same as the Japanese standard BSA of $1.48 \mathrm{~m}^{2}$, which is clearly lower than the Western standard value of $1.73 \mathrm{~m}^{2}$. Therefore, a possible reason for the higher incidence of AEs and discontinuations due to AEs in the SD group of this study was that there were many patients with multiple variables.

In addition, the number of patients who became intolerant due to toxicity in the latest treatment prior to IRd therapy was zero $(0 \%)$ in the DE group and one $(14 \%)$ in the SD group. The failure to motivate to continue treatment due to the development of relatively strong gastrointestinal symptoms after ixazomib administration may have led to early interruption and discontinuation. In contrast, in the DE group, as shown in Figure 1 and Table III, it is presumed that the majority of patients had minimal non-haematological toxicity at the start of IRd therapy. Thus, it was possible to continue treatment smoothly.

This study has some limitations. It was a retrospective analysis and had a very small number of patients from which to draw a valid conclusion. The lack of pharmacokinetic sampling data is another major limitation. In addition, because the dose-escalation method for ixazomib in the DE group was at the discretion of the physician, an optimal and detailed strategy is unclear. Thereby, specific methods for dose titration are needed, and a prospective study with a larger number of patients is desirable.

In conclusion, the results of our study indicate that IRd therapy by titration from a low dose of ixazomib may reduce treatment interruption due to AEs and allow treatment to continue without negatively affecting effectiveness.

\section{Conflicts of Interest}

The Authors have no conflicts of interest to declare.

\section{Authors' Contributions}

$\mathrm{YO}, \mathrm{KH}$, and $\mathrm{AY}$ designed the study and prepared the article. YO, MY, KT, CO, DN, TK, SB, HU, TY, and AY observed the patients and collected clinical data. YO, DN, YY, and AY analysed the data. All Authors read and approved the final version of the article.

\section{References}

1 Kumar SK, Rajkumar SV, Dispenzieri A, Lacy MQ, Hayman SR, Buadi FK, Zeldenrust SR, Dingli D, Russell SJ, Lust JA, Greipp PR, Kyle RA and Gertz MA: Improved survival in multiple myeloma and the impact of novel therapies. Blood 111(5): 2516-2520, 2008. PMID: 17975015. DOI: 10.1182/ blood-2007-10-116129

2 Chim CS, Kumar SK, Orlowski RZ, Cook G, Richardson PG, Gertz MA, Giralt S, Mateos MV, Leleu X and Anderson KC: Management of relapsed and refractory multiple myeloma: Novel agents, antibodies, immunotherapies and beyond. Leukemia 32(2): 252-262, 2018. PMID: 29257139. DOI: 10.1038/leu.2017.329

3 National Comprehensive Cancer Network Clinical Practice Guidelines in Oncology (NCCN guidelines $\left.{ }^{\circledR}\right)$ multiple myeloma version2.2020. Available at: https://www.nccn.org/professionals/ physician_gls/pdf/myeloma.pdf. [Last accessed on April 29th 2020]

4 Moreau P, Masszi T, Grzasko N, Bahlis NJ, Hansson M, Pour L, Sandhu I, Ganly P, Baker BW, Jackson SR, Stoppa AM, Simpson DR, Gimsing P, Palumbo A, Garderet L, Cavo M, Kumar S, Touzeau C, Buadi FK, Laubach JP, Berg DT, Lin J, Di Bacco A, Hui AM, van de Velde H, Richardson PG: Oral ixazomib, lenalidomide, and dexamethasone for multiple myeloma. N Eng1 J Med 374(17): 1621-1634, 2016. PMID: 27119237. DOI: 10.1056/NEJMoa1516282

5 Richardson PG, Weller E, Lonial S, Jakubowiak AJ, Jagannath S, Raje NS, Avigan DE, Xie W, Ghobrial IM, Schlossman RL, Mazumder A, Munshi NC, Vesole DH, Joyce R, Kaufman JL, Doss D, Warren DL, Lunde LE, Kaster S, Delaney C, Hideshima T, Mitsiades CS, Knight R, Esseltine DL and Anderson KC: Lenalidomide, bortezomib, and dexamethasone combination therapy in patients with newly diagnosed multiple myeloma. Blood 116(5): 679-686, 2010. PMID: 20385792. DOI: 10.1182/ blood-2010-02-268862

6 Stewart AK, Rajkumar SV, Dimopoulos MA, Masszi T, Spicka I, Oriol A, Hajek R, Rosinol L, Siegel DS, Mihaylov GG, Goranova-Marinova V, Rajnics P, Suvorov A, Niesvizky R, Jakubowiak AJ, San-Miguel JF, Ludwig H, Wang M, Maisnar V, Minarik J, Bensinger WI, Mateos MV, Ben-Yehuda D, Kukreti V, Zojwalla N, Tonda ME, Yang X, Xing B, Moreau P, Palumbo $\mathrm{A}$ and Investigators $\mathrm{A}$ : Carfilzomib, lenalidomide, and dexamethasone for relapsed multiple myeloma. N Engl J Med 372(2): 142-152, 2015. PMID: 25482145. DOI: 10.1056/ NEJMoa1411321

7 Suzuki K, Handa H, Chou T, Ishizawa K, Takubo T and Kase Y: Phase 1 study of ixazomib alone or combined with lenalidomidedexamethasone in Japanese patients with relapsed/refractory multiple myeloma. Int J Hematol 105(4): 445-452, 2017. PMID: 28000099. DOI: $10.1007 / \mathrm{s} 12185-016-2149-1$

8 United Nations: Department of Economic and Social Affairs, Population Division, 2019. World Population Prospects 2019, Data Booklet. Available at: https://population.un.org/wpp/ Publications/Files/WPP2019_DataBooklet.pdf [Last accessed on April 29th 2020]

9 Ozaki S, Handa H, Saitoh T, Murakami H, Itagaki M, Asaoku H, Suzuki K, Isoda A, Matsumoto M, Sawamura M, Konishi J, Sunami K, Takezako N, Hagiwara S, Kuroda Y, Chou T, Nagura $\mathrm{E}$ and Shimizu K: Trends of survival in patients with multiple myeloma in Japan: A multicenter retrospective collaborative 
study of the Japanese Society of Myeloma. Blood Cancer J 5: e349, 2015. PMID: 26383822. DOI: 10.1038/bcj.2015.79

10 Bekaii-Saab TS, Ou FS, Ahn DH, Boland PM, Ciombor KK, Heying EN, Dockter TJ, Jacobs NL, Pasche BC, Cleary JM, Meyers JP, Desnoyers RJ, McCune JS, Pedersen K, Barzi A, Chiorean EG, Sloan J, Lacouture ME, Lenz HJ and Grothey A: Regorafenib dose-optimisation in patients with refractory metastatic colorectal cancer (REDOS): A randomised, multicentre, open-label, phase 2 study. Lancet Oncol 20(8): 1070-1082, 2019. PMID: 31262657. DOI: 10.1016/s14702045(19)30272-4

11 Wendtner CM, Hallek M, Fraser GA, Michallet AS, Hillmen P, Durig J, Kalaycio M, Gribben JG, Stilgenbauer S, Buhler A, Kipps TJ, Purse B, Zhang J, De Bedout S, Mei J and ChananKhan A: Safety and efficacy of different lenalidomide starting doses in patients with relapsed or refractory chronic lymphocytic leukemia: Results of an international multicenter double-blinded randomized phase II trial. Leuk Lymphoma 57(6): 1291-1299, 2016. PMID: 26763349. DOI: 10.3109/ 10428194.2015 .1128540

12 Kumar SK, Bensinger WI, Zimmerman TM, Reeder CB, Berenson JR, Berg D, Hui AM, Gupta N, Di Bacco A, Yu J, Shou Y and Niesvizky R: Phase 1 study of weekly dosing with the investigational oral proteasome inhibitor ixazomib in relapsed/refractory multiple myeloma. Blood 124(7): 1047-1055, 2014. PMID: 24904120. DOI: 10.1182/blood-2014-01-548941

13 Us Department of Health and Human Services: Common Terminology Criteria for Adverse Events (CTCAE) v4.03. Available at: https://evs.nci.nih.gov/ftp1/CTCAE/CTCAE_4.03/ CTCAE_4.03_2010-06-14_QuickReference_8.5x11.pdf. [Last accessed on April 29th 2020]

14 Blumenthal GM, Gong Y, Kehl K, Mishra-Kalyani P, Goldberg KB, Khozin S, Kluetz PG, Oxnard GR and Pazdur R: Analysis of time-to-treatment discontinuation of targeted therapy, immunotherapy, and chemotherapy in clinical trials of patients with non-small-cell lung cancer. Ann Oncol 30(5): 830-838, 2019. PMID: 30796424. DOI: 10.1093/annonc/mdz060

15 Palumbo A, Rajkumar SV, San Miguel JF, Larocca A, Niesvizky R, Morgan G, Landgren O, Hajek R, Einsele H, Anderson KC, Dimopoulos MA, Richardson PG, Cavo M, Spencer A, Stewart AK, Shimizu K, Lonial S, Sonneveld P, Durie BG, Moreau P and Orlowski RZ: International Myeloma Working Group Consensus Statement for the management, treatment, and supportive care of patients with myeloma not eligible for standard autologous stemcell transplantation. J Clin Oncol 32(6): 587-600, 2014. PMID: 24419113. DOI: $10.1200 / \mathrm{JCO} .2013 .48 .7934$

16 Kanda Y: Investigation of the freely available easy-to-use software 'EZR' for medical statistics. Bone Marrow Transplant 48(3): 452-458, 2013. PMID: 23208313. DOI: 10.1038/bmt. 2012.244

17 Palumbo A and Anderson K: Multiple myeloma. N Engl J Med 364(11): 1046-1060, 2011. PMID: 21410373. DOI: 10.1056/ NEJMra1011442

18 Gupta N, Hanley MJ, Harvey RD, Badros A, Lipe B, Kukreti V, Berdeja J, Yang H, Hui AM, Qian M, Zhang X, Venkatakrishnan $\mathrm{K}$ and Chari A: A pharmacokinetics and safety phase $1 / 1 \mathrm{~b}$ study of oral ixazomib in patients with multiple myeloma and severe renal impairment or end-stage renal disease requiring haemodialysis. Br J Haematol 174(5): 748-759, 2016. PMID: 27196567. DOI: $10.1111 /$ bjh. 14125
19 Gupta N, Hanley MJ, Venkatakrishnan K, Perez R, Norris RE, Nemunaitis J, Yang H, Qian MG, Falchook G, Labotka R and $\mathrm{Fu}$ S: Pharmacokinetics of ixazomib, an oral proteasome inhibitor, in solid tumour patients with moderate or severe hepatic impairment. Br J Clin Pharmacol 82(3): 728-738, 2016. PMID: 27121262. DOI: 10.1111/bcp.12991

20 Gupta N, Hanley MJ, Xia C, Labotka R, Harvey RD and Venkatakrishnan K: Clinical pharmacology of ixazomib: The first oral proteasome inhibitor. Clin Pharmacokinet 58(4): 431449, 2019. PMID: 30117017. DOI: 10.1007/s40262-018-0702-1

21 Gupta N, Goh YT, Min CK, Lee JH, Kim K, Wong RS, Chim CS, Hanley MJ, Yang H, Venkatakrishnan K, Hui AM, Esseltine DL and Chng WJ: Pharmacokinetics and safety of ixazomib plus lenalidomide-dexamethasone in asian patients with relapsed/refractory myeloma: A phase 1 study. J Hematol Oncol 8: 103, 2015. PMID: 26337806. DOI: 10.1186/s13045-0150198-1

22 Hou J, Jin J, Xu Y, Wu D, Ke X, Zhou D, Lu J, Du X, Chen X, Li J, Liu J, Gupta N, Hanley MJ, Li H, Hua Z, Wang B, Zhang X, Wang H, van de Velde H, Richardson PG and Moreau P: Randomized, double-blind, placebo-controlled phase III study of ixazomib plus lenalidomide-dexamethasone in patients with relapsed/refractory multiple myeloma: China continuation study. J Hematol Oncol 10(1): 137, 2017. PMID: 28683766. DOI: 10.1186/s13045-017-0501-4

23 Kumar SK, Berdeja JG, Niesvizky R, Lonial S, Laubach JP, Hamadani M, Stewart AK, Hari P, Roy V, Vescio R, Kaufman JL, Berg D, Liao E, Di Bacco A, Estevam J, Gupta N, Hui AM, Rajkumar V and Richardson PG: Safety and tolerability of ixazomib, an oral proteasome inhibitor, in combination with lenalidomide and dexamethasone in patients with previously untreated multiple myeloma: An open-label phase 1/2 study. Lancet Oncol 15(13): 1503-1512, 2014. PMID: 25456369 DOI: 10.1016/s1470-2045(14)71125-8

24 Varga G, Nagy Z, Demeter J, Kosztolanyi S, Szomor A, Alizadeh H, Deak B, Schneider T, Plander M, Szendrei T, Varoczy L, Illes A, Batai A, Peto M and Mikala G: Real world efficacy and safety results of ixazomib lenalidomide and dexamethasone combination in relapsed/refractory multiple myeloma: Data collected from the hungarian ixazomib named patient program. Pathol Oncol Res 25(4): 1615-1620, 2019. PMID: 30712192. DOI: 10.1007/s12253-019-00607-2

25 Kakimoto $\mathrm{Y}$ and Hoshino M: The interim analysis of postmarketing surveillance of ixazomib for relapsed/refractory multiple myeloma, focusing on early discontinued cases. Int $\mathbf{J}$ Myeloma 9: 148, 2019. http://www.jsm.gr.jp/files/shourokupdf/ jsm44.pdf. [Last accessed on April 29th 2020] 